\title{
BRAGANTIA
}

Revista Científica do Instituto Agronômico, Campinas

Vol. 39

Campinas, outubro de 1980

Artigo $\mathrm{n}^{\circ} 12$

\section{FIXAÇÃO DE FÓSFORO EM SOLOS DO ESTADO DE SÃO PAULO ${ }^{(1)}$}

José Antonio Jorge (2), Seção de Pedologia, Instituto Agronômico

\section{RESUMO}

Em amostras representativas de oito unidades de solos do Estado de Sāo Paulo, mediu-se quantitativamente a fixação de fósforo em função da concentração da soluçāo fosfatada, do tempo de contato da amostra com essa solução, do umedecimento e secagem da amostra, e da ausência de matéria orgânica e de ferro.

Duas foram as concentraçōes das soluções fosfatadas: 0,03 e 0,03N em $\mathrm{PO}_{4}^{3-}$. Excetuando o Grande Grupo Podzolizado de Lins e Marilia, var. Marilia, todas as unidades fixaram significativamente mais fósforo com a soluçāo mais concentrada. Com respeito ao tempo de contato com a solução, a fixação foi maior no maior tempo, exceto na amostra do referido Grande Grupo de Solos (P 902).

A secagem e o umedecimento alternados das amostras só causaram incremento na fixação de fósforo no latossolo vermelho-escuro, fase arenosa, e podzolizado de Lins e Marilia, var. Lins.

A oxidação da matéria orgânica propiciou aumento da fixação de fósforo nos solos podzólico vermelho-amarelo e podzolizado de Lins e Marília, var. Lins; ocorreu menor fixação no latossolo roxo.

Os solos cujos óxidos de ferro haviam sido removidos fixaram menos fósforo do que os solos integrais e os solos sem matéria orgânica.

\section{INTRODUÇĀO}

Denomina-se fixação de fósforo à retenção de fosfatos na fase sólida do solo. Muitos são os fatores que podem influir nessa retenção, tendo si- do estudados principalmente os que se relacionam com o comportamento físico-químico dos colóides, a constituição mineralógica dos solos, a concentração hidrogeniônica da solução, os catíons associados com o fosfato e a

(1) Recebido para publicaçăo a 20 de novembro de 1979.

(") Com bolsa de suplementação do CNPq. 
matéria orgânica. Os agentes mais importantes responsáveis pela diminuição da solubilidade do fosfato pela precipitação ou adsorção superficial são o ferro e o alumínio, em solos ácidos, e o cálcio, em solos neutros e alcalinos.

O fenômeno de fixação do fósforo vem sendo estudado em várias partes do mundo, há algumas décadas. Já por volta de 1930, conforme citação de ROMINE \& METZGER (18), Truog \& Ford afirmavam que os solos amarelados fixavam fósforo mais prontamente que os avermelhados, devido à diferença nos compostos de ferro, e chegaram à conclusão de que os solos escuros, ricos em matéria orgânica, tinham geralmente baixa capacidade de fixação do elemento.

$O$ fósforo apresenta-se em formas dinâmicas no solo. LINDSAY \& MORENO (15), estudando o equilíbrio do fosfato nos solos, relacionam o $\mathrm{Fe}^{3+}, \mathrm{Al}^{3+}, \mathrm{Ca}^{2+}, \mathrm{Mg}^{2+}, \mathrm{K}^{+}$, $\mathrm{NH}_{4}^{+}, \mathrm{H}^{+}, \mathrm{OH}^{-}$e o F${ }^{-}$como íons que potencialmente podem reagir com o fosfato.

JOHN (13), estudando 343 solos do Canadá, concluiu que os fatores mais importantes na fixação de fósforo são o pH, Ca, P, Al, Fe, matéria orgânica e granulometria do solo.

CAMARGO et alii $(6,7)$ confirmaram que, embora o $\mathrm{pH}$ e a presença de cations trocáveis influenciem a fixação do fósforo em solo, a natureza deste é o fator mais importante na ocorrência do fenômeno. Confirmaram, ainda, aumento do índice de fixação de fósforo, em função do tempo de contato do elemento com o solo.

Segundo BARROW (3), contudo, à medida que se adicionam fosfatos aos solos, estes vão reduzindo sua capacidade de fixar mais fósforo.

Referindo-se à complexidade do fenômeno de fixação de fósforo, DEAN (12) alerta que, sendo os métodos para sua determinação empíricos, é necessário controlar cuidadosamente certos fatores, como concentração de fósforo adicionado, tempo de contato, temperatura e $\mathrm{pH}$, a fim de conseguir reprodutividade nos resultados. Esse autor define a fixaçāo de fósforo como a sua conversão a uma forma menos solúvel. A fim de evitar confusão entre solubilidade do fosfato e disponibilidade propriamente às plantas, Dean considera fósforo fixado aquele retido na fase sólida do solo.

Embora escassos, há alguns estudos sofre fixação de fósforo em solos do Estado de São Paulo. CATANI \& GLÓRIA (8) estudaram a capacidade de fixação de fósforo de alguns solos, pela técnica de troca isotópica, com o uso de fósforo radioativo $\mathrm{P}^{32}$. Algumas das conclusões gerais obtidas por esses autores foram: o fenômeno de troca isotópica atingiu o equilíbrio quando a solução fosfatada (com fósforo comum e radioativo) foi mantida em contato com o solo durante 16 horas; os solos arenosos, pobres em óxidos hidratados de ferro e alumínio, fixaram menos fósforo que os argilosos, com teores médios de óxidos.

CATANI \& PELLEGRINO (9), estudando a fixação de fósforo em amostras de terra roxa e terra roxa misturada, obtiveram resultados situados entre 10 e $24 \mathrm{meq}$ de $\mathrm{PO}_{4}{ }^{3-}$ por $100 \mathrm{~g}$ de terra, os quais muito se aproximam dos obtidos neste trabalho ( $P$ 928), quando se usou solução fosfatada de concentração semelhante à 
empregada pelos autores citados $\left(0,03 \mathrm{~N}\right.$ em $\left.\mathrm{PO}_{4}{ }^{3-}\right)$.

ANASTÁCIO (1), estudando numerosos solos brasileiros, concluiu que, de maneira geral, os latossolos retêm mais fósforo que os podzólicos. Concluiu, ainda, que a fixação não foi proporcional ao grau de acidez dos solos pesquisados.

SÃ et alii (19), estudando a adsorção máxima de fósforo no solo calculada pela isoterma de Langmuir em dezesseis unidades de mapeamento dos solos da Zona da Mata de Pernambuco, concluíram que a adsorção de $P$ aumenta com o incremento do teor de argila do solo; a retenção de $P$ se deu tanto pela superfície das partículas como pela interação $\mathrm{P} \times \mathrm{Al}$ trocáveis; essa relação $\mathrm{P} \times \mathrm{Al}$ torna-se importante na adsorção de fósforo em solos com níveis de alumínio trocável ao redor de 1 meq por $100 \mathrm{~g}$ de solo; há significativamente correlação entre a adsorção máxima de $\mathrm{P}$ e a porcentagem de umidade equivalente (superfície específica).

\section{BITTENCOURT \& ZAMBEL-} LO JR. (4) encontraram altas correlações entre a adsorção máxima de fósforo $\mathrm{e}$ os teores de óxido de ferro livre, não encontrando, todavia, correlação alguma com os teores de sesquióxido de alumínio extraídos com $\mathrm{NaOH} 0,5 \mathrm{~N}$.

DABIN (11) salienta que, mesmo nos solos de regiões tropicais com alto poder de fixação de fósforo, principalmente naqueles ácidos e ricos em sesquióxidos livres, a fixação de fósforo não é um fenômeno irreversível.

PARFITT et alii (16), utilizando técnicas espectroscópicas com infravermelho, estudaram a reação super- ficial entre os óxidos de ferro e íons fosfatados. Dois íns de oxidrila na superfície, ou moléculas de água, são substituídos por um íon de fosfato. Dessa forma, dois átomos de oxigênio do fosfato são coordenados, cada um a um íon $\mathrm{Fe}^{3+}$ diferente, resultando numa superfície complexa do tipo $\mathrm{Fe}-0-\mathrm{P}\left(\mathrm{O}_{2}\right)-0-\mathrm{Fe}$.

RAJAN \& FOX (17) explicam que a adsorção de fosfatos em solos tropicais está associada à liberação de aníons, tais como os sulfatos e silicatos. Aumentando-se, contudo, a concentração, os fosfatos provavelmente são fixados por outras reações, como a quebra de polímeros de óxidos hidratados.

Os solos do Estado de São Paulo possuem grande capacidade fixadora de fósforo. Nesse aspecto, BARROW (2) salienta que é importante determinar a capacidade de fixação dos solos para vários aníons, tais como fosfatos, sulfatos e molibdatos.

Quanto à nutrição das plantas, embora se alimentem largamente da forma $\mathrm{H}_{2} \mathrm{PO}_{4}^{-}$, segundo BUEHER (5), através da exsudação, pelas raízes, de dióxido de carbono, é possível a absorção de aníons $\mathrm{HPO}_{4}{ }^{-2}$.

Embora a maioria das plantas cultivadas não absorva mais de 20 ou $30 \mathrm{~kg}$ de fosfato por hectare, sabe-se que é mister colocar à disposição das raízes, de três a quatro vezes a quantidade requerida pela planta, a fim de garantir o seu desenvolvimento e proJução.

Neste trabalho são apresentados os resultados de determinações quantitativas de fixação de fósforo em amostras representativas de oito Grandes Grupos de Solos do Estado de São Paulo. 


\section{MATERIAL E METODOS}

Para ter uma visão generalizada do poder de fixação de fósforo dos solos do Estado de São Paulo, utilizaram-se oito unidades, cujas características físicas e químicas se acham no quadro 1.

Procedeu-se à fixação de fósforo em amostras tomadas de sub-horizontes $A_{1}$.

Essas unidades já tinham sido objeto de pesquisa desenvolvida por JORGE \& VALADARES (14), para o estudo das formas de fósforo segundo o método de fracionamento de CHANG \& JACKSON (10), sendo, portanto, conhecidos os respectivos teores originais de $\mathbf{P}$ total, os quais constam do quadro 1 .

Como fontes fornecedoras de fósforo, utilizaram-se soluções de $\mathrm{Ca}\left(\mathrm{H}_{2} \mathrm{PO}_{4}\right)_{2} \cdot \mathrm{H}_{2} \mathrm{O}$ de concentrações 0,03 e $0,3 \mathrm{~N}$ em $\mathrm{PO}_{4}{ }^{3-}$, cujos $\mathrm{pH}$ eram 3,3 e 2,5 respectivamente.

Considerando, de acordo com numerosos autores, que a fixação inicial é bastante grande, empregaram-se três tempos de contato da solução com a amostra de solo: meia hora, duas horas e dez dias.

Além dos tratamentos em que a amostra de terra ficou em suspensão na solução fosfatada, procurou-se verificar a influência do umedecimento e secagem alternados, durante dez dias, mantendo-se durante 24 horas o solo em suspensão e, em seguida, centrifugando o material e recolhendo em um copo a solução fosfa- tada sobrenadante, deixando a amostra secar parcialmente ao ar. A relação solo:solução usada foi $2 \mathrm{~g}: 20 \mathrm{ml}$.

O procedimento para a fixação de fósforo seguido neste trabalho pode ser sumarizado da seguinte maneira:

a) Em um tubo de centrífuga colocaram-se $2 \mathrm{~g}$ de terra passada na peneira $0,21 \mathrm{~mm}\left({ }^{2}\right)$;

b) Adicionaram-se $20 \mathrm{ml}$ da solução fosfatada;

c) Arrolhou-se o tubo, agitando-o a cada quinze minutos; no caso da incubação por dez dias, agitou-se o tubo a cada hora, apenas durante o dia; no tratamento 10 "U", deixou-se a amostra em contato com a solução fosfatada durante dez dias, ao passo que no tratamento 10 " $R$ " provocou-se o umedecimento e secagem alternados, pela centrifugação e recolhimento da solução a cada 24 horas; a solução recolhida em copinhos foi utilizada para o reumedecimento do respectivo solo; dessa forma, o solo permaneceu encharcado durante 24 horas e apenas úmido nas 24 horas seguintes;

d) Completado o tempo de incubação, centrifugou-se, eliminando-se o sobrenadante;

e) Efetuaram-se as sucessivas lavagens com solução alcoólica a $80 \%$, utilizando $20 \mathrm{ml}$ em cada lavagem ( ${ }^{3}$ );

f) Deixou-se a amostra secar até o dia seguinte;

g) Procedeu-se ao ataque com $\mathrm{H}_{2} \mathrm{SO}_{4}$, concentrado com $20 \mathrm{ml}$ por amostra e, aproximadamente, igual

(2) Nos casos dos perfis $844,902,949$ e 953 , de baixo poder de fixação, no tratamento ccm solução fosfatada $0,03 \mathrm{~N}$ em $\mathrm{PO}_{4}{ }^{3}$, empregaram-se $4 \mathrm{~g}$ de terra.

(i) As prévias indicaram a necessidade de sete lavagens quando se utilizou solo integral ou com a matéria orgânica oxidada e solução fosfatađa $0,3 \mathrm{~N}$, e de cinco lavagens quando se empregou a solução $0,03 \mathrm{~N}$. No caso dos solos cujo ferro tinha sido removido, foram necessárias respectivamente, cinco e três lavagens. 

quantidade de água usada na transferência da terra dos tubos da centrífuga para os frascos de Kjeldahl; o ataque durou cerca de três horas;

h) Dosou-se o fósforo por colorimetria $\left(^{4}\right)$.

Na série "solos sem matéria orgânica", esta foi oxidada pela $\mathrm{H}_{2} \mathrm{O}_{2}$ a 100 volumes, na base de $2 \mathrm{mI}$ para cada grama de terra; repetiu-se a operação uma vez, tendo-se o cuidado de manter o $\mathrm{pH}$ a um nível inferior a 5,8 , usando $a$ indicador bromo cresol verde, a fim de evitar interferência do manganês. Terminado o primeiro ataque, lavou-se o solo com água destilada e procedeu-se a um segundo ataq̨ue. Essas duas operações foram suficientes para os fins deste trabalho, conforme indicam os dados do quadro 2.
$\mathrm{Na}$ série "solos sem ferro", este foi removido através de sua redução e complexação com ditionito e citrato de sódio. $O$ teor de ferro livre das diferentes amostras estudadas acha-se no quadro 1 .

Para simplificar a tabulação dos dados, denominamos solução $A$ e $B$ às de concentração 0,03 e $0,3 \mathrm{~N}$ respectivamente; "fase", a cada série de amostras de terra: integral, sem matéria orgânica ou sem ferro; e 10 $\mathrm{U}$ e $10 \mathrm{R}$, respectivamente, amostras que permaneceram constantemente em contato com as soluções de fosfato durante dez dias, e amostras que, a períodos certos de 24 horas, nesse mesmo espaço de dez dias, eram umedecidas e secas, conforme descrição feita no item $C$.

QUADRO 2. - Oxidação da matéria orgânica pelo peróxido de hidrogênio a 100 volumes e influência no pH de solos do Estado de São Paulo (suborizontes)

\begin{tabular}{|c|c|c|c|c|c|}
\hline \multirow{2}{*}{ Perfil } & \multicolumn{2}{|c|}{ Carbono } & \multirow{2}{*}{$\begin{array}{l}\text { Perda de } \\
\text { matéria orgânica }\end{array}$} & \multicolumn{2}{|c|}{$\mathrm{pH}$} \\
\hline & Inicial & Final & & Original & Final \\
\hline & 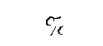 & 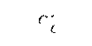 & ¿: & & \\
\hline 803 & 4,96 & 0,37 & 6,9 & 4,95 & 5.10 \\
\hline 928 & 2,19 & 0,47 & 3.0 & 6,80 & 6,10 \\
\hline 945 & 2,02 & 0,33 & 2.9 & 6,00 & 660 \\
\hline 902 & 0,64 & 0,22 & 0,7 & 5,80 & 6,70 \\
\hline 949 & 2,27 & 0.15 & 3,6 & 6,40 & 7,20 \\
\hline 844 & 0,94 & 0.02 & 1.6 & 5,50 & 6.90 \\
\hline 947 & 3,20 & 0.20 & 5,2 & 5,50 & 6,30 \\
\hline 953 & 1,24 & 005 & 2,1 & 5,20 & 7,20 \\
\hline
\end{tabular}

(4) Neste trabalho empregou-se um colorímetro Klet-Summerson, com filtro 66 (660nm) e subcarbonato de bismuto e ácido ascórbico como reagentes. 
Foram considerados os seguintes tratamentos no estudo das três fases:

\section{Fase}

Solo integral

Solo integral

Solo integral

Solo integral

Solo menos mat. org.

Solo menos mat. org.

Solo menos mat. org.

Solo menos mat. org.

Solo menos ferro

Solo menos ferro

Solo menos ferro

Solo menos ferro
Concentração da solução fosfatada

$\begin{array}{ll}0,3 & \text { (B) } \\ 0,3 & \text { (B) } \\ 0,03 & \text { (A) } \\ 0,03 & \text { (A) } \\ 0,3 & \text { (B) } \\ 0,3 & \text { (B) } \\ 0,03 & \text { (A) } \\ 0,03 & \text { (A) } \\ 0,3 & \text { (B) } \\ 0,3 & \text { (B) } \\ 0,03 & \text { (A) } \\ 0,03 & \text { (A) }\end{array}$

Período de incubação

Meia hora

Duas horas

Meia hora

Duas horas

Meia hora

Duas horas

Meia hora

Duas horas

Meia hora

Duas horas

Meia hora

Duas horas
Todas as determinações foram feitas sempre com duas repetições de cada tratamento, e os dados obtidos foram comparados com auxílio da análise estatística.

\section{RESULTADOS E DISCUSSÃO}

No quadro 3 constam os dados médios de fixação de fósforo pelos oito Grandes Grupos de Solos estu. dados, nas diferentes fases, tempos de incubação e concentrações da solução fosfatada.

\subsection{Latossolo vermelho-amarelo - Perfil 803}

\section{a) Solo integral}

A análise estatística revelou diferença altamente significativa entre os tratamentos. Decompondo-os, verificou-se diferença significativa, ao nível de $1 \%$, entre as concentrações e os tempos de incubação; foi igualmente significativa a interação concentração $x$ tempo de incubação. $O$ coeficiente de variação foi de $4,4 \%$.

Pelo teste de Tukey, constataram-se diferenças altamente significativas entre as duas concentrações de soluções fosfatadas, em todos os tempos de incubação.

No que diz respeito ao tempo de contato da solução fosfatada com os solos, não houve diferença significativa para essa unidade de solo entre meia e duas horas e tampouco entre os tratamentos " $R$ " e "U". Contudo, entre o período de incubação de meia ou de duas horas contrastado com o de dez dias ("R" ou " $U$ "), os resultados foram significativos ao nível de $1 \%$ pelo teste de Scheffé.

b) Solo integral $x$ solo sem matéria orgânica $x$ solo sem ferro

A análise estatística mostrou diferença altamente significativa entre os 
Vol. 39 , Art. n. ${ }^{\circ} 12$

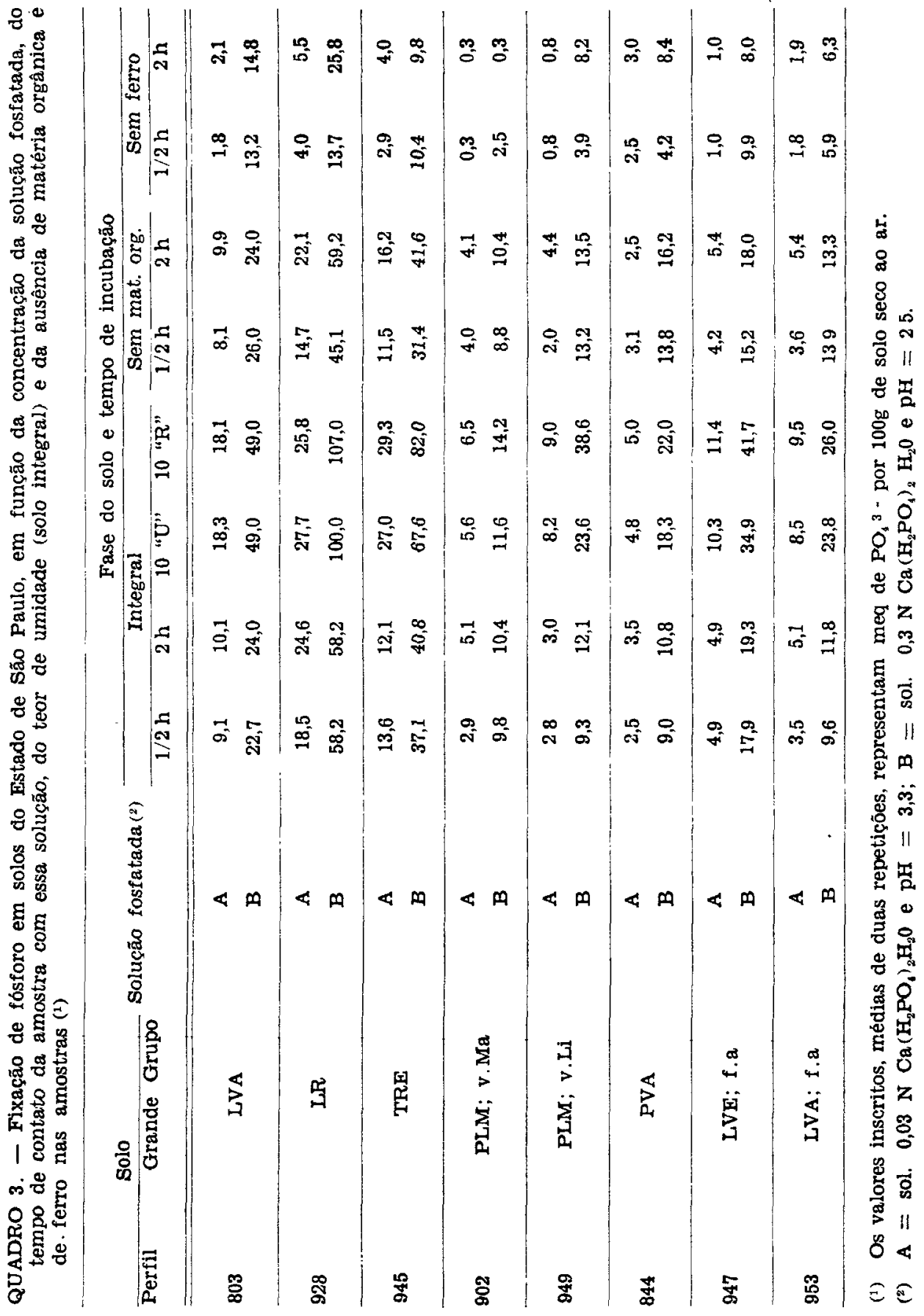


tratamentos. Decompondo-os, verificou-se existir diferença altamente significativa entre as concentrações e entre as fases. Entre os tempos de incubação não foram constatadas diferenças significativas.

As interações concentração $x$ tempo, concentraçāo $x$ fase, tempo $x$ fase e tempo $x$ concentração $x$ fase nāo foram significativas.

Em todas as fuses consideradas, a fixação obtida com a solução $B$ foi significativamente maior do que com a solução A (ao nível de 1\%).

Entre solo integral e solo menos matéria orgânica, não houve diferença significativa, porém ambos diferem, ao nível de I\% pelo teste de Scheffé, da fase "menos ferro". de $15 \%$.

O coeficiente de variação foi

\subsection{Latossolo roxo - Perfil 928}

\section{a) Solo integral}

A análise estatística revelou diferença altamente significativa entre os tratamentos. Decompondo-os. verifificou-se diferença altamente significativa entre as concentrações: foi igualmente significativa a interação concentração $x$ tempo de incubação. $O$ coeficiente de variação foi de $7,6 \%$.

Pelo teste de Tukey, ao nível de $1 \%$, constataram-se diferenças significativas entre as duas concentraçōes de soluções fosfatadas, em todos os tempos de incubação.

No que se refere ao tempo de incubação dos solos, não houve diferença significativa entre meia e duas horas, tampouco entre os tratamentos "R" e "U". Contudo, entre o período de incubação de meia ou de duas horas contrastado com o de dez dias ("R" e "U"), os resultados foram significativos a $1 \%$, pelo teste de Scheffé.

b) Solo integral $x$ solo sem matéria orgânica $x$ solo sem ferro

A análise estatística mostrou diferença altamente significativa entre os tratamentos. Decompondo-os, constatou-se diferença significativa, ao nível de $1 \%$, entre as concentrações, entre tempos de incubação e entre fases.

As interações concentração $x$ fase, tempo $x$ fase e tempo $x$ concentração $x$ fase foram altamente significativas; a interação concentração $x$ tempo foi significativa a $5 \%$.

Em todas as fases consideradas, a fixação obtida com a solução $B$ foi significativamente maior do que com a solução A (1\%).

Entre solo integral e solo menos matéria orgânica, houve diferença significativa a $5 \%$; por sua vez, ambos diferem, ao nível de $1 \%$, pelo teste de Scheffé, da fase "menos ferro". Conforme consta no quadro 2 , a retirada da matéria orgânica desse solo causou um abaixamento no seu $\mathrm{pH}$, fato contrário ao que se observou nos outros perfis estudados.

$O$ coeficiente de variação foi de $5,4 \%$.

\subsection{Terra roxa estruturada - Perfil 945}

\section{a) Solo integral}

A análise estatística demonstrou diferença altamente significativa entre 
os tratamentos. Decompondo-os, verificou-se diferença altamente significativa entre as concentrações e entre os tempos de incubação; foi significativa, a $5 \%$, a interação concentração x tempo de incubação. O coeficiente de variação foi de $15 \%$.

Pelo teste de Tukey, constataram-se diferenças significativas entre as duas concentraçöes, sendo a $5 \%$ nos tempos de contato de meia e duas horas, e a $1 \%$, tratando-se do tempo de contato de dez dias.

Quanto ao tempo de incubação, não houve diferença significativa entre meia e duas horas, tampouco entre os tratamentos " $R$ " $e$ " $U$ ". Contudo, entre os periodos de incubação de meia e duas horas contrastados com o de dez dias ("R" e "U"), os resultados foram significativos a $5 \%$ para o tratamento "R" e a $1 \%$ para o tratamento "U", pelo teste de Scheffé.

b) Solo integral $x$ solo sem matéria orgânica $x$ solo sem ferro

A análise estatística revelou diferença altamente significativa entre os tratamentos. Decompondo-os, constataram-se diferenças altamente significativas entre as concentrações e entre as fases, e a $5 \%$ entre os tempos de incubação.

As interações concentração $\mathbf{x}$ fase $e$ tempo $x$ fase foram significativas a $1 \%$; não foram significativas as interações concentração $x$ tempo $e$ tempo $x$ concentração $x$ fase.

Em todas as fases, a fixação obtida com a solução $B$ foi significativamente maior do que com a solução A, ao nível de $1 \%$.

Entre solo integral e solo menos matéria orgânica não houve diferença significativa, porém ambos diferem, ao nível de $1 \%$, pelo teste de Scheffé, da fase menos ferro. $9,7 \%$.

O coeficiente de variação foi de

\subsection{Podzolizado de Lins e Marília, var. Marilia - Perfil 902}

\section{a) Solo integral}

A análise estatística revelou diferença altamente significativa entre os tratamentos. Decompondo-os, verificou-se diferença significativa a $1 \%$ entre as concentrações; não houve diferença significativa entre os tempos de incubação, tampouco com a interação concentração $x$ tempo de incubação. $O$ coeficiente de variação foi de $25,7 \%$.

Embora se constatassem diferenças altamente significativas entre as duas concentrações, pelo teste de Tukey elas não diferiram quando se considerou o mesmo tempo de contato.

\section{b) Solo integral $x$ solo sem ma- téria orgânica $x$ solo sem ferro}

A análise estatística mostrou diferença altamente significativa entre os tratamentos. Decompondo-os, verificou-se diferença altamente significativa entre as concentrações, entre os tempos de incubação e entre as fases.

As interações concentração $x$ fase $e$ concentração $x$ tempo $x$ fase foram significativas a $1 \%$, enquanto as interações concentração $x$ tempo $e$ tempo $x$ fase foram significativas a $5 \%$.

Em todas as fases, a fixação obtida com a solução B foi significativa- 
mente maior do que com a solução A $(1 \%)$.

Entre solo integral e solo menos matéria orgânica não houve diferença significativa, porém ambos diferiram, ao nivel de $1 \%$ pelo teste de Scheffé, da fase "menos ferro". $6,7 \%$.

O coeficiente de variação foi de

\subsection{Podzolizado de Lins e Marília, var. Lins - Perfil 949}

\section{a) Solo integral}

A análise estatística demonstrou diferença altamente significativa entre os tratamentos. Decompondo-os, verificou-se diferença altamente significativa entre as concentrações e entre os tempos de incubação: foi igualmente significativa a interação concentração $x$ tempo de incubação. $7,8 \%$.

O coeficiente de variação foi de

Pelo teste de Tukey, constataram-se diferenças altamente significativas entre as duas concentrações em todos os tempos de incubação.

Quanto ao tempo de incubação, não houve diferença significativa entre e meia e duas horas; verificou-se, porém, diferença altamente significativa entre esses dois períodos e a incubação de dez dias ("R" e "U"), sendo igualmente significativa a diferença entre "R" e "U", pelo teste de Scheffé.

b) Solo integral $x$ solo sem matéria orgânica $x$ solo sem ferro

A análise estatística revelou diferença altamente significativa entre os tratamentos. Decompondo-os, verificou-se diferença significativa a $1 \%$ entre as concentrações, entre os tempos de incubação e entre as fases.

As interações concentração $x$ fase e concentração $x$ tempo de incubação $x$ fase foram significativas a $1 \%$; a interação concentração $\mathrm{x}$ tempo de incubação foi significativa a $5 \%$. Não foi significativa a interação tempo de incubação $x$ fase.

Em todas as fases, a fixação obtida com a solução $\mathbf{B}$ foi significativamente maior do que com a solução A (prob. 1\%).

Entre solo integral e solo menos matéria orgânica não houve diferença significativa, porém ambos diferiram, ao nível de $1 \%$ pelo teste de Scheffé, da fase "menos ferro".

O coeficiente de variação foi de $10,4 \%$.

\subsection{Podzólico vermelho-amarelo - Perfil 844}

a) Solo integral

A análise estatística revelou diferença altamente significativa entre os tratamentos. Decompondo-os, constataram-se diferenças altamente significativas entre as concentrações e os tempos de incubação; foi igualmente significativa a interação concentração $x$ tempo de incubação. $O$ coeficiente de variação foi de $9,9 \%$.

Pelo teste de Tukey, verificaram-se diferenças altamente significativas entre as duas concentrações, em todos os tempos de incubação.

Quanto ao tempo de contato da solução fosfatada, não houve diferença significativa entre meia e duas horas, tampouco entre os tratamentos "R" e "U". Contudo, para o período de incubação de meia ou de duas 
horas contrastado com o de dez dias (" $R$ " ou " $U$ "), os resultados foram significativos a $1 \%$ pelo teste de Scheffé.

\section{b) Solo integral $x$ solo sem matéria orgânica $x$ solo sem ferro}

A análise estatística revelou diferença altamente significativa entre os tratamentos. Decompondo-os, constataram-se diferenças altamente significativas entre as concentrações, entre os tempos de incubação e entre as fases.

As interações concentração $\mathbf{x}$ tempo de incubação e concentração $x$ fase foram significativas a $1 \%$; a interação concentração $x$ tempo de incubação $x$ fase foi significativa a $5 \%$, porém a interação tempo de incubação $\mathbf{x}$ fase não foi significativa. Em todas as fases, a fixação obtida com a solução $\mathrm{B}$ foi significativamente maior do que com a solução A (prob. 1\%).

Tomando os resultados de fixação obtidos com a solução B, obteve-se diferença altamente significativa entre solo integral e solo menos matéria orgânica; ambos, por sua vez, apresentaram diferença significativa, ao nível de $1 \%$ pelo teste de Scheffé, da fase "menos ferro".

$\mathrm{Na}$ concentração A não se constataram diferenças significativas entre solo integral, solo menos matéria orgânica e sclo menos ferro. $8,3 \%$.

O coeficiente de variação foi de

\subsection{Latossolo vermelho-escuro, fase arenosa — Perfil 947}

\section{a) Solo integral}

A análise estatística revelou diferença significativa entre os tratamen- tos. Decompondo-os, constataram-se diferenças altamente significativas entre as concentrações e entre os tempos de incubação; foi igualmente significativa a interação concentração $x$ tempo de incubaçāo. $O$ coeficiente de variação foi de $4,7 \%$.

Pelo teste de Tukey, verificaram-se diferenças altamente significativas entre as duas concentrações, em todos os tempos de incubação.

Quanto ao tempo de contato da solução fosfatada, não houve diferença significativa entre meia e duas horas; verificou-se, porém, diferença altamente significativa entre esses dois períodos e a incubação de dez dias ("R" e "U"), sendo igualmente significativa entre " $R$ " $e$ " $U$ ".

\section{b) Solo integral $x$ solo sem matéria orgânica $x$ solo sem ferro}

A análise estatística revelou diferença altamente significativa entre os tratamentos. Decompondo-os, constataram-se diferenças significativas a $1 \%$ entre as concentraçōes e entre as fases, porém não entre os tempos de incubação.

A interação concentração $x$ fase foi significativa a $1 \%$; não foram significativas as interações concentraçãa $x$ tempo de incubação, tempo $x$ fase e tempo $x$ concentração $x$ fase.

Em todas as fases, a fixação obtida com a solução B foi significativamente maior do que com a solução A (prob. 1\%).

Entre solo integral e solo menos matéria orgânica, não houve diferença significativa, porém ambos diferiram, ao nível de $1 \%$ pelo teste de Scheffé, da fase "menos ferro". 

$12,3 \%$.

O coeficiente de variação foi de

\subsection{Latossolo vermelho-amarelo, fase arenosa - Perfil 953}

\section{a) Solo integral}

A análise estatística revelou diferença altamente significativa entre os tratamentos. Decompondo-os, constatou-se diferença significativa a $1 \%$ entre as concentrações e entre os tempos de incubação; foi igualmente significativa a $1 \%$ a interação concentração $x$ tempo de incubação. $O$ coeficiente de variação foi de $6,2 \%$.

Pelo teste de Tukey, verificaram-se diferenças altamente significativas entre as duas concentrações em todos os tempos de incubação.

No que se refere ao tempo de incubação, não houve diferença significativa entre meia $e$ duas horas, tampouco entre os tratamentos " $R$ " e "U". Contudo, entre os períodos de incubação de meia ou de duas horas contrastado com o de dez dias ("R" ou "U"), os resultados foram significativos a $1 \%$ pelo teste de Scheffé.

b) Solo integral $x$ solo sem matéria orgânica $x$ solo sem ferro

A análise estatística revelou diferença altamente significativa entre os tratamentos. Decompondo-os, constataram-se diferenças altamente significativas entre as concentrações e entre as fases, sendo significativa a $5 \%$ a diferença entre os tempos de incubação.

A interação concentração $x$ fase foi altamente significativa; as interações concentração $x$ tempo de incubação, tempo de incubação $x$ fase $e$ tempo de incubação $x$ fase $x$ concentração rĩo foram significativas.

Em todas as fases consideradas, a fixação obtida com a solução $B$ foi significativamente maior do que com a solução A (prob. 1\%).

Entre solo integral e solo menos matéria orgânica, não houve diferença significativa; contudo, ambos, por sua vez, diferiram ao nível de $1 \%$ pelo teste de Scheffé, da fase "menos ferro". $14,0 \%$.

$O$ coeficiente de variação foi de

\section{CONCLUSÕES}

a) Para todos os solos estudados a análise estatística revelou diferença altamente significativa entre os tratamentos.

b) Ambas as concentrações da solução fosfatada apresentaram diferenças significativas, ao nível de $1 \%$, em todas as unidades de solos.

c) Quanto ao tempo de incubação do solo integral, as diferenças foram altamente significativas em todos os perfis, salvo no $P$ 902, onde não se registrou diferença significa¿iva.

d) Considerando as três fases estudadas, constatou-se diferença altamente significativa nos tempos de incubação dos perfis $928,902,949$ e 844; a diferença foi significativa a $5 \%$ nos P 945 e 953 , e não significativa nos P 803 e 947.

e) As fases "solo integral" e "solo menos matéria orgânica" diferiram em todos os perfis estudados, ao nível de $1 \%$, da fase "solo menos ferro". Contrastando, nas fases "solo 
Vol. 39, Art. n. ${ }^{\circ} 12$

integral" $x$ "solo menos matéria orgânice", constataram-se diferenças altamente significativas nos perfis 928 e 844; a diferença foi significativa a $5 \%$ no P 949. Na fase "solo menos matéria orgânica", a fixação de fósforo foi menor apenas no P 928 (latossolo roxo).

f) Verificou-se diferença significativa a $1 \%$ entre os tratamentos
" $R$ " e " $U$ " apenas nos perfis 947 e 949 , quando se utilizou a solução fosfatada mais concentrada (B).

g) Para os perfis estudados, constatou-se a seguinte ordem decrescente de fixação de fósforo: $P 928>$ P $945>$ P $803>$ P $947>$ P $949>$ P $953>$ P $844>$ P 902, sendo maior nos latossolos e terra roxa estruturada do que ncs podzólicos.

\section{PHOSPHORUS FIXATION CAPACTTY OF EIGHT SOILS OF THE STATE OF SÃO PAULO, BRAZIL}

\section{SUMMARY}

Eight different soils of the State of São Pau'o were studied as to their phosphorus fixation capacity. The effect of concentration of the phosphate solution, time of contact of the solution with the soil and alternatively drying and wetting the sample was also evaluated.

Fixation tests were performed with undisturbed soil samples as well as with samples of which organic matter and iron oxides had been removed.

Phosphorus fixation was higher in latosols and "terra roxa estruturada" than in podzolic soils but decreased in all soils upon removal of iron oxides. Removal of organic matter and the drying-and-wetting process increased fixation in some cases and decreased it in others.

\section{BIBLIOGRAFIA}

1. ANASTACIO, M. L. A. Fixação de fósforo nos solos brasileiros. Rio de Janeiro, Ministério da Agricultura, EPFS, 1968. 12p. (Bol. Técnico, 4)

2. BARROW, N. J. Comparison of the adsorption of molybdate, sulfate and phosphate by soils. Soil Sci., 109:282-288, 1970.

3. Effect of previous additions of phosphate on phosphate adsorption by soils. Soil Sci., 118:82-89, 1974.

4. BITTENCOURT, V. C. \& ZAMBELLO JR., E. Comportamento do fósforo em solos tropicais. I. Isotermas de adsorção. Piracicaba, Centro de Energia Nuclear na Agricultura, 1973. 23p. (BC-012)

5. BUEHRER, T. F. The physico-chemical relationship of soli phosphates. Tueson, University of Arizona, 1932. p.155-212. (Tech. Bulletin, 42)

6. CAMARGO, O. A.; RAIJ, B. VAN \& GROHMANN, F. Fixação do fósforo em solos avaliada pelo índice de Bache e Willians e sua correlação com outras propriedades. Ciência e Cultura, São Paulo, 26:681-685, 1974.

7. —— Influência de cations trocáveis e pH na fixação do fósforo em solos. Ciência e Cultura, São Paulo, 28:678-681, 1976. 
8. CATANI, R. A. \& GLÓRIA, N. A. Evaluation of the capacity of phosphorus fixation by the soil through the isotopic exchange, using $\mathrm{p}^{32}$. Anais da Escola Superior de Agricultura Luiz de Queiroz, Piracicaba, 21:230-237, 1964.

9. \& PELLEGRINO, D. Avaliação da capacidade de fixaçāo de fósforo pelo solo. Anais da Escola Superior de Agricultura Luiz de Queiroz, Piracicaba, $17: 237-252,1960$.

10. CHANG, S. E. \& JACKSON, M. L. Fractionation of soil phosphorus. Soil Sci., 84:113-144, 1957.

11. DABIN, B. fvolution des phosphates en sols acides des régions tropicales. Science du Sol, $2: 87-104,1974$.

12. DEAN, L. A. Fixation of soil phosphrous. Advances in Agronomy, 1:391-411, 1949.

13. JOHN, M. K. Factors affecting the adsorption of microamounts of tagged phosphorus by soils. Communications in Soil Science and Plant Analysis, 3:197-205, 1972.

14. JORGE, J. A. \& VALADARES, J. Formas de fósforo em solos do Estado de São Paulo. Bragantia, Campinas, $28: 23-30,1969$.

15. LINDSAY, W. L. \& MORENO, E. C. Phosphate phase equilibria in soils. Proceedings Soils Science Society of America, 24:177-182, 1960.

16. PARFTTT, R. L.; ATKINSON, R. J. \& SMART, R. St. C. The mechanism of phosphate fixation by iron oxides. Procedings soil Science Society of American, $39: 837-841,1975$.

17. RAJAN, S. S. S. \& FOX, R. L. Phosphate adsorption by soils: II. Reactions in tropical acid soil. Procedings Soil Science Society of America, 39:846-851, 1975.

18. ROMINE, D. S. \& METZGER, W. N. Phosphorus fixation by horizon of various soil types in relation to dilute acid extractable iron and aluminum. Journal American Society of Agronomy, 31:99-108, 1939.

19. SÁ JUNIOR, P. M.; GOMES, I. F. \& VASCONCELLOS A. Retenção de fósforo em solos da Zona da Mata de Pernambuco. Pesquisa Agropecuária, Brasilia, 3:183-188, 1968. 